\title{
Investigation of Expected Seismic Performance on Existing Buildings: A Case Study
}

\author{
Arun Kumar ${ }^{1}$, Ajay Singh Chauhan ${ }^{2}$, Khushpreet Singh $^{3}$, Aditya Tiwary ${ }^{4}$ \\ 1, 2, (PG student, Department of Civil Engineering, Chandigarh University, Gharaun Punjab, India) \\ 3, 4 (Assistant Professor, Department of Civil Engineering, Chandigarh University, Gharaun Punjab, India) \\ ('arunsharma4u39388@gmail.com, ${ }^{1}$ ajaysinghc8@gmail.com, ${ }^{3}$ khushpreet85@yahoo.com, \\ ${ }^{4}$ adadtiwary15@gmail.com)
}

\begin{abstract}
In India the Himalayan belt lies near the fault separating Indo-Australian and Eurasian plate. But it is natural that this area is seismically active and lies in earthquake zone IV. Beside this fact, most of buildings in Himachal Pradesh have poor structural and constructional quality. In this paper, an effort has been made for determining the study of different structural irregularities and construction defects of buildings situated in Solan and Shimla district of Himachal Pradesh, India. Various factors which were considered in the survey are cantilever slab loaded above, offsets, soft storey, unequal heights of the column, long column short column, overhanging beams, open ground storey etc. other factors those were considered like segregation, exposed bars, verticality of columns, poor bricks quality were also included in the study that cause damages in the structure during earthquake. At last some remedies had been suggested for the mentioned defects and irregularities of the structures.
\end{abstract}

Keywords- Earthquake, irregularities, offsets, segregation, seismic zone, soft storey.

\section{INTRODUCTION}

The irregularities in the structures are due to architectural, functional and economic constraints. It is basically done on mass, stiffness or strength on seismic demand. The main reason of these irregularities is due to elastic story shears, overturning, drift as well as inelastic drift and energy dissipation. In this paper, study has been made for determining the constructional defects and structural irregularities of buildings situated in Solan and Shimla district of Himachal Pradesh. A building that lacks discontinuity in geometry, symmetry, mass, or load resisting elements is called as irregular building. The main focus of this case study is to enhance our knowledge regarding, ill effects of irregularities on seismic performance of earthquake resistant buildings and to suggest some possible remedial measures and precautions that must be taken at planning and construction stages of buildings. Recent earthquakes takes place in India are at Nepal (more than 8000 killed and 21000 injured), Manipur and Assam (11 dead, 200 injured). The certain failure of buildings is due to the irregularities these includes masonry failure, shear failure, structural failure like stiffness irregularity, pounding effect, mass irregularities, vertical and horizontal projection, column failure twisting of buildings, ductile detailing, overhanging column, setbacks, offset etc. the structure which has the ability to undergo deformation without any failure is called ductility. And the term ductile detailing has been in earthquake engineering for determining up to which a structure can undergo large deformation without collapsing. Limited number of studies has been done on irregularities of the building. ${ }^{[4]}$ This paper tells us that two methods have been used for determining the mass irregularities in multi storey structure. The two methods are the equivalent static force procedure and the response spectrum analysis method.

\section{STRUCTURAL IRREGULARITIES}

\section{Pounding}

The term pounding has been one of the serious causes for severe building damages in earthquake. The nonstructural damage involves movement across separation and pounding between two adjacent structures as shown in fig.1. The pounding has been occurred between two adjacent building during an earthquake is due to difference in dynamic characteristics between the buildings. For providing the minimum separation distance between the two buildings is according to either by international building code or by seismic design code. Lopez Garcia gives a formula for the separation of building or providing spacing by below formula

$$
\mathbf{S}=\mathbf{U}_{\mathbf{a}}+\mathbf{U}_{\mathrm{b}}
$$


Where,

$\mathrm{S}=$ Separation distance

$\mathrm{U}_{\mathrm{a},} \mathrm{U}_{\mathrm{b}}=$ Peak displacement response of adjacent structures ' $a$ ' and ' $\mathrm{b}$ '.

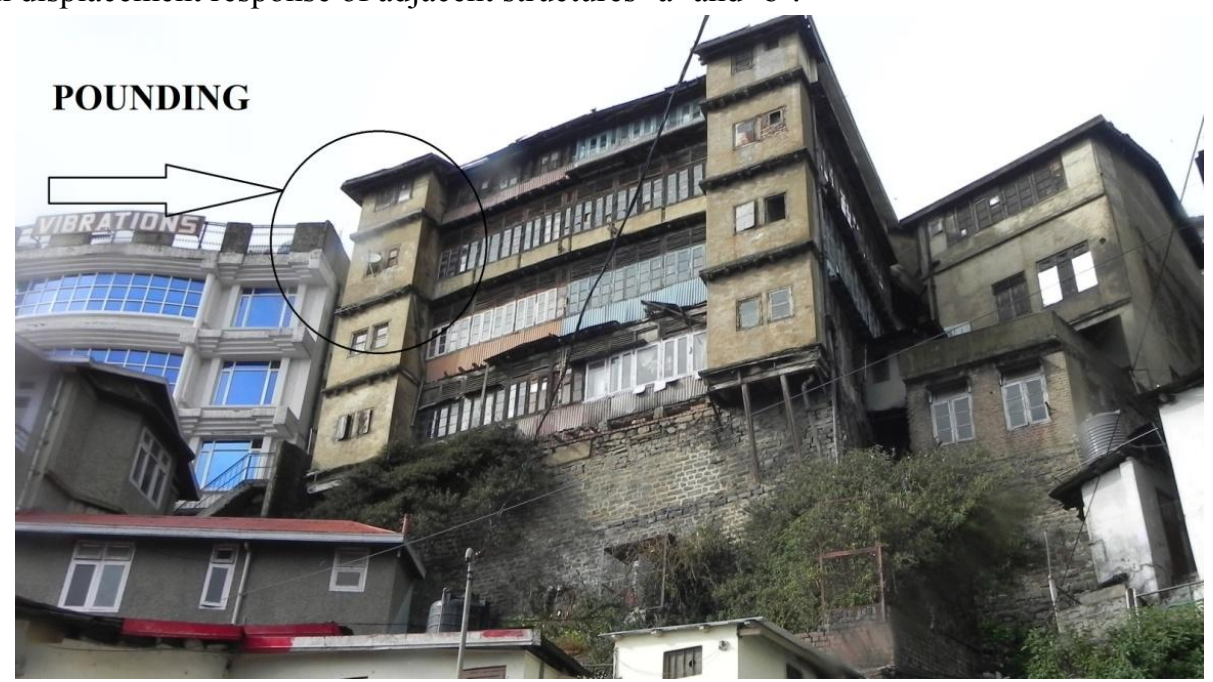

Fig 1: Pounding defect

\section{Soft story}

A soft story building is also called as a multi-story building which have one or more floors that includes windows, wide doors, unobstructed commercial space and openings where a shear wall be required to provide stability in earthquake engineering design. ${ }^{[12]}$ fig. 2 shows that a soft story has level less than $70 \%$ or $80 \%$ from the average stiffness of above three floors.

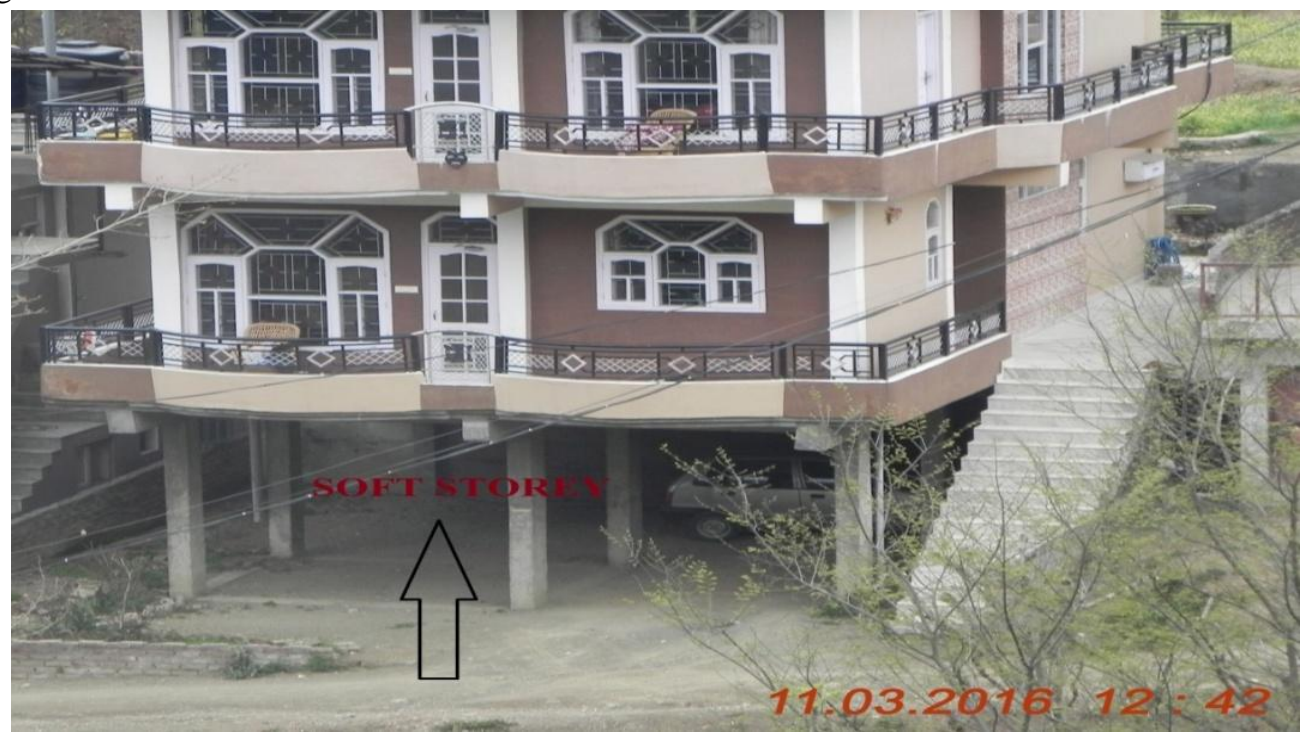

Fig 2: Soft Storey Building

\section{Size of columns}

For providing a column in the construction some procedure or design requirement as per given in code has been followed. The structural defects in columns are shown in fig. 3. The minimum dimension of column shall not be less than (a) 15 times the largest beam bar diameter of the longitudinal reinforcement in the beam passing through or anchoring into the column joint, and (b) $300 \mathrm{~mm}$. The basic thumb rule those had to be followed is:

1. Size of column.

2. Columns distance between two.

3. Columns alignment. 


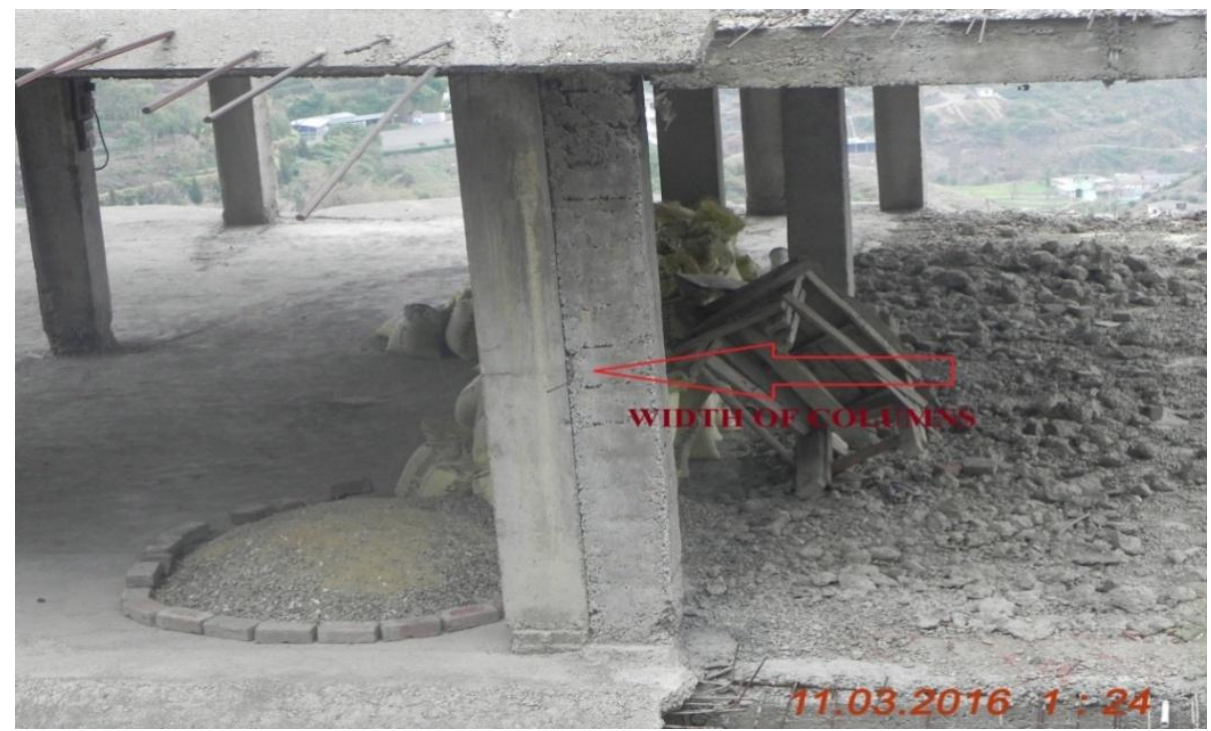

\section{Floating columns}

Fig 3: Structural defects due to improper width of columns

Floating column is considered as that column which is hanging on the structure and transferring its load to the ground level or the column is provided on the ground level but on the first floor no column is there and above that weight is there which result into collapse of the structure. It rest on abeam which is a horizontal member. Fig. 4 shows that the main drawbacks of this column are that it totally divert its load to below level where no column is provided that result into collapse of the structure. The column is hanging in the middle of the story which leads to the failure of the building due to shear and overturning. Floating columns has not been covered in any IS code.

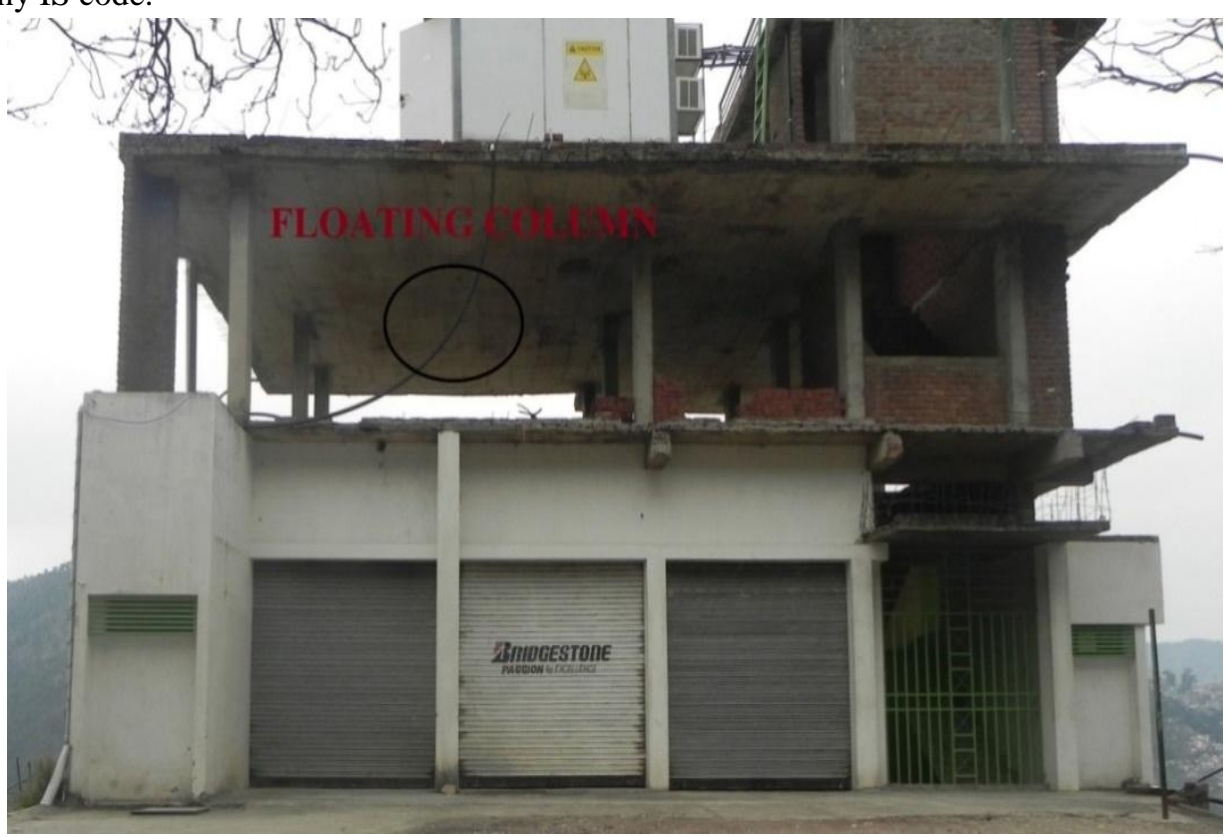

Fig 4: floating columns

\section{Long column and short column}

When the effective length of the column is less than 12 it is called short column and when the effective length of column is less than 45 it is long column. Figure 5 shows that the columns have unequal height along the slope that will cause structural effects like damage and twisting in shorter columns. These types of construction are generally occurred in slope ground that causes structural damage in the buildings during earthquake. 


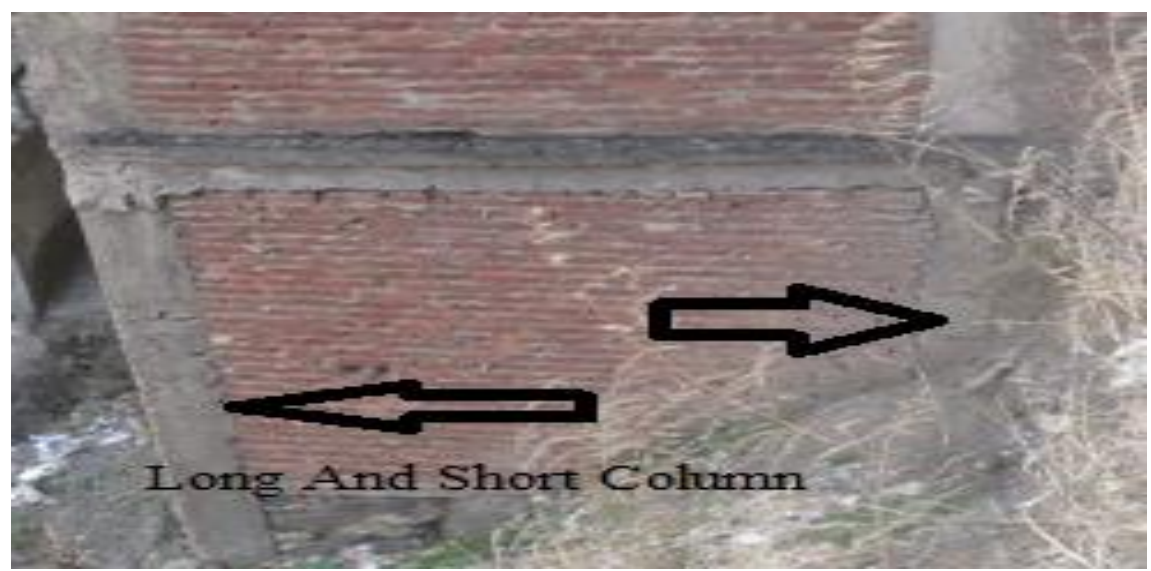

Fig 5: Long and short column defect

Offset

Offset is basically defined as the alignment defects in the column of the structure .the structure shown in the figure 6 is located in Solan district and is under construction. The building has three storeys and is constructed with brick infill panels. Figure shows that the column that is under construction has shown offset in them. The result of misalignment during construction between the two columns results in collapse during an earthquake.

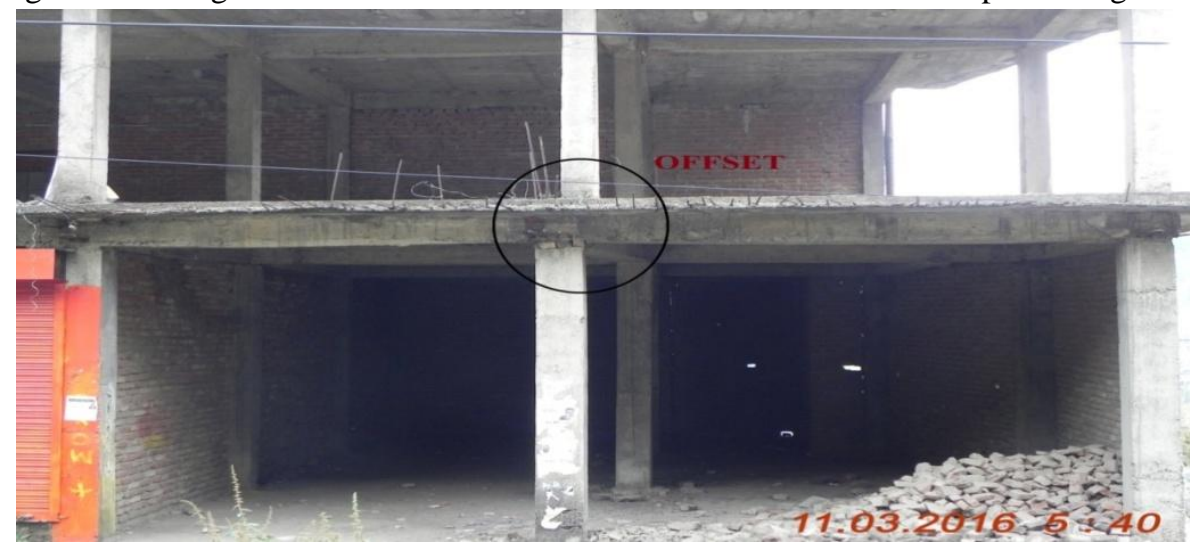

Fig 6: Offset in layout of columns

\section{Setbacks}

According to IS 1893 (PART 1) 2002, building with setbacks causes two types of problem that is immediate jump in earthquake forces at the phase of irregularity and torsion. Fig. 7shows that only the half portion of the base of the building has been utilized which results in the collapse of structure.

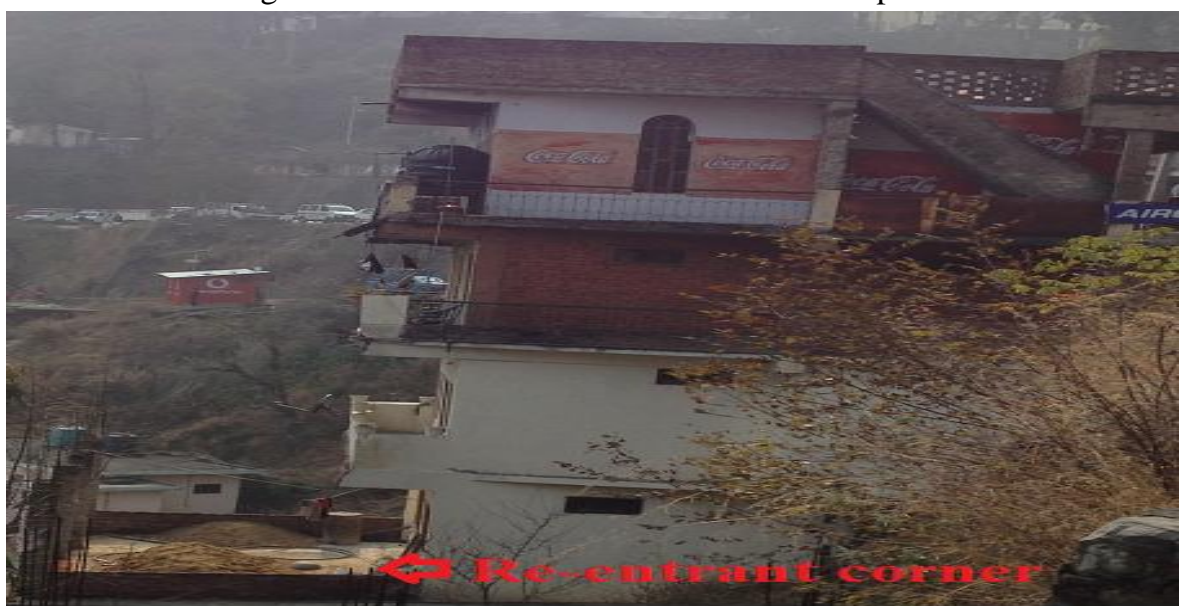

Fig7: Re-entrant corner 


\section{Cantilever slab loaded above}

This is the portion in the building that has been used as a free space like balconies with low load capacity.

Fig. 8 show the commercial building located in market of Solan district. The extra weight that has been loaded above will result in collapse during an earthquake. In order to rectify this column has been provided below the slab, so that the above load will be distributed on it.

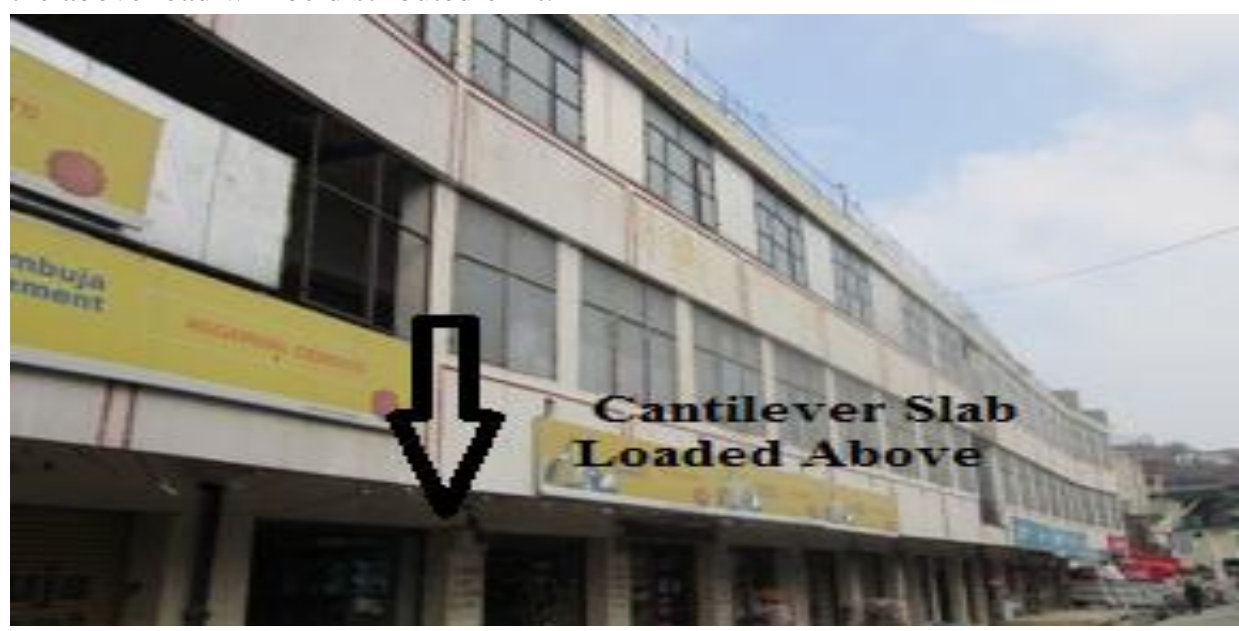

Fig 8: Structural defect due to cantilever slab loaded above

\section{REMEDIAL MEASURES}

Following are the safety measures to prevent future destruction due to earthquake

- Column failure- As per IS 13920 :1993 provision special arrangements has been made to increase the adequate toughness and ductility which results in making the column capable of undergoing dissipating seismic energy and extensive inelastic deformation in a stable manner. [11]

- Soft storey- As per IS 1893: 2002 provision has given for soft storey is that the lateral stiffness is less than $70 \%$ from the above storey and also less than $80 \%$ from the average lateral stiffness of the above stories. The columns of the soft storey are to be designed 2.5 times the storey shear and its moment should be calculated under seismic loads. [12]

- Pounding- As per IS 1893: 2002 two adjacent units or two adjacent buildings with separation joint in between them shall be separated by a equal distance to the amount R times the sum of calculated story displacement to avoid the collapse of the structure when two units of the buildings will be deflected towards each other. [12]

- $\quad$ Building design- All the reinforced structural buildings has to be designed as per the IS 456, IS 1893:2002 and IS 13920.if designing of the building is executed as per above mentioned codes, it will reduces the failure of the structure. [12]

- Re-entrant corners - As per IS 1893:2002 both of the projection of the structure for re-entrant corner are greater than 15 percent of dimensions in the given direction. [12]

- Mass irregularities - As per IS 1893:2002, this provision of mass irregularities has been existed where the seismic weight of any storey is greater than 200 percent to that of adjacent storey. [12]

- Shear walls - As per IS 13920 the thickness of any part of shear wall shall not be less than $150 \mathrm{~mm}$ and the minimum reinforcement ratio provided is 0.0025 of the gross area. [11]

- Joints - provision for joints given in IS 13920 is that it should not be less than the-0.92/Fy (Tv-Pu /Ag) where Tv is factored shear stress at joint and Ag is gross cross sectional area of the joint. [11]

- Workmanship: At the time of constructional phase of building it is necessary to execute work according to specifications as well as proper designing. Work should be executed under the presence of engineer. The foundation of the structure should be earthquake resistant. 


\section{CONCLUSION}

After doing study of the various buildings in Solan and Shimla district, it has been found that there is large number of structural irregularities in the buildings located in these regions. As we know that Himachal Pradesh lies in zone IV and V, so there are more chances of damages due to occurrence of an earthquake in this zone. So to reduce the structural irregularities in the structures there are some provisions that are given in IS 13920:1993 and IS 1893:2002that should be adopted at the time of planning, designing and executing phases of the constructional work. By locating the vertical resistant element and mass distribution, the torsional effect which results in the failure of the structure can be minimised. The structure should be detailed as per IS 13920:1993 and IS 456:2007.

\section{REFERENCES}

[1] A. Tena-Colunga, "Evaluation of the seismic response of slender, setback RC moment-resisting frame buildings designed according to the seismic guidelines of a modern seismic codell,, In 13th world conference on earthquake engineering, Paper no.2027, Canada, 2004.

[2] R. S. Thyagarajan and W. D. Iwan ,"Performance characteristics of a widely used hysteretic model in structural dynamics", In proceedings of fourth U.S. National conference on Earthquake engineering, Earthquake engineering research institute (EERI), Vol.2, pp. 177 - 186,1990.

[3] M. Tomaževǐc c, and W. Polona Weiss, "Displacement capacity of masonry buildings as a basis for the assessment of behavior factor: an experimental study”, Bullitten of earthquake engineering, Vol.8, pp.1267 - 1294, April 2010.

[4] R. Tremblay and L. Poncet, "Seismic performance of concentrically braced steel frames in multistory buildings with mass irregularity", Journal of Structural Engineering, Vol.131, pp.1363-1375. September 2005.

[5] K. C. Tsai, C. P. Hsiao and M. Brunaeu, Overview of building damages in Chi Chi Earthquakell, Earthquake engineering and Engineering Seismology, Vol.2, No.1, pp.93 - 108, March 2000.

[6] J.H.Casis and E. Cornejo "Influence of vertical irregularities in there sponge of the earthquake resistance structures", Eleventh World Conference on Earthquake Engineering.

[7] P. Devesh Soni and B. Bharat Mistry," Qualitative Review Of Seismic Response Of Vertically Irregular Building Frames”, ISET Journal of Earthquake Technology, Vol. 43, No. 4, , pp. 121-132,December 2006,.

[8] Milind V. Mohod and Nikita A. Karwa, Seismic Behaviour of Setback Buildings, International Journal of Innovative Research in Science, Engineering and Technology, Vol. 3, Issue 9, pp. 15871-15878, September 2014.

[9] F. Alba, A. G. Ayala and R. Bento, "Seismic performance evaluation of plane frames regular and irregular in elevation", In Proceedings of the 4th European workshop on the seismic behavior of irregular and complex structures, CD ROM, Thessaloniki, August 2005.

[10] E. Alderighi and W. Salvatore, "Structural fire performance of earthquake resistant composite steel-concrete framesl", Vol.31, No.4, pp. 894 - 909, August 2009.

[11] IS 13920:1993, Ductile Detailing Of Reinforced Concrete Structures Subjected To Seismic Forces — Code Of Practice.

[12] IS 1893:2002, Criteria for Earthquake Resistant Design Of Structures. 